\title{
Another aspect of figurine function
}

\author{
Takamune Kawashima \\ Department of Humanities \& Social Sciences, University of Tsukuba, Japan \\ k_takamune@nyc.odn.ne.jp
}

\begin{abstract}
In Japan, it is suggested that clay figurines were produced for deliberate fragmentation. However, the distribution of clay figurines was limited to some sites, and the total number of fragmented figurines is relatively small. This article tries to present some new arguments about the function of figurines, based on data from Angyo period, late and latest Jomon. I suggest that the function of figurines needs further discussion.
\end{abstract}

IZVLEČEK - Po mnenju nekaterih so na Japonskem keramične kipce izdelovali zato, da so jih nato namensko razdrobili. Vendar je razširjenost keramičnih kipcev omejena le na nekatera najdišča, celotno število fragmentiranih kipcev pa je relativno majhno. V tem članku bom poskušal predstaviti nekaj novih dokazov o uporabnosti kipcev, osnovanih na podatkih iz obdobja Angyo - pozno in zaključno obdobje kulture Jomon. Menim, da je potrebna nadaljnja diskusija o uporabnost teh kipcev.

KEY WORDS - Japan; Jomon; Angyo period; Clay figurine; distribution; function

\section{INTRODUCTION}

Clay figurines were made in the European Neolithic, but also during the Japanese prehistoric age (Fig. 1), called the Jomon period, which is considered equivalent to the Neolithic. In the Jomon period (Tab. 1), over 11000 anthropomorphic clay figurines were produced. The number of figurines produced in prehistoric Japan differs from other East Asian countries. The production of figurines is known from the Korean and Chinese Neolithic, but the number of figurines in Japan is much higher. In spite of the fact that figurines were made mainly in the Middle East, Europe, Mesoamerica and Japan, figurines in each area have common characteristics, such as female representation.

Until now, among Japanese archaeologists, the deliberate fragmentation of figurines was an accepted hypothesis. It is well known that most figurines were discovered in fragments. However, the matter is still open to further discussion. In this article, I will focus on anthropomorphic clay figurines in Japan, consi- der the fragmentation hypothesis, and try to analyse the social function of figurines from a specific area.

\section{THE HISTORY OF JOMON FIGURINE STUDIES}

In the early stages of Japanese archaeology, figurines attracted archaeologists' attention because their shape represents the human body. In the latter part of the $19^{\text {th }}$ century, when the new government was established, not only historians and anthropologists, but also archaeologists paid attention to ancient ethnic groups in Japan and their customs. Therefore, archaeologists believed that decorations on figurines represented body art, the design of clothing and so on. Figurines were thought to have been used as toys for children, as statues of gods or goddesses, ornaments, and as amulets for an easy birth. Since most figurines represent female characteristics, it was suggested that figurines represented Mother Goddesses like the European figurines. However, 
this view was criticised, since the Jomon economy was based on hunting, fishing and gathering.

Even in the early stages of figurine study, the deliberate fragmentation hypothesis, which suggests that figurines were broken to cure some part of a person, appeared. Later, this hypothesis changed to the idea that fragmented figurines were thrown away around settlements in order to secure a rich harvest. Anthropological data from Indonesian folklore (Jensen 1966) was added to this hypothesis (Yoshida 1986). A famous story of the Wemale tribe of Indonesia is about Hainuwele, a girl able to produce everything from her own body. The village benefits from her mysterious power, but after a short time people start to envy her power and kill her. Instructed by Hainuwale, her mother fragments her body and buries it in various locations. It is said that from those locations the main vegetables of the tribe sprang up. Similar stories existed around the Pacific Ocean rim, including North America. Yoshida suggested that the same type of myth and ritual customs existed in Jomon society (Yoshida 1986.37-41).

From the analysis of figurines, it was suggested that they were made from some pieces which could be easily broken (Ono 1984). Ono insisted that figurines were made for fragmentation, and that the technique for making figurines was a reflection of fragmentation in the ritual system (cf. Chapman 2000). However, there is an opinion that these techniques merely imply the method of production (Fujinuma 1997. 154-155) and that the motive for making figurines should not be limited to fragmentation.

\section{THE SEQUENCE OF TYPOLOGICAL STUDIES}

As well as studies on the function of figurines, along with increasing discoveries of figurines, there have also been studies in chronology and regional differences. Ono classified figurines into 15 groups according to sex and distribution (Ono 1910). Kono insis-

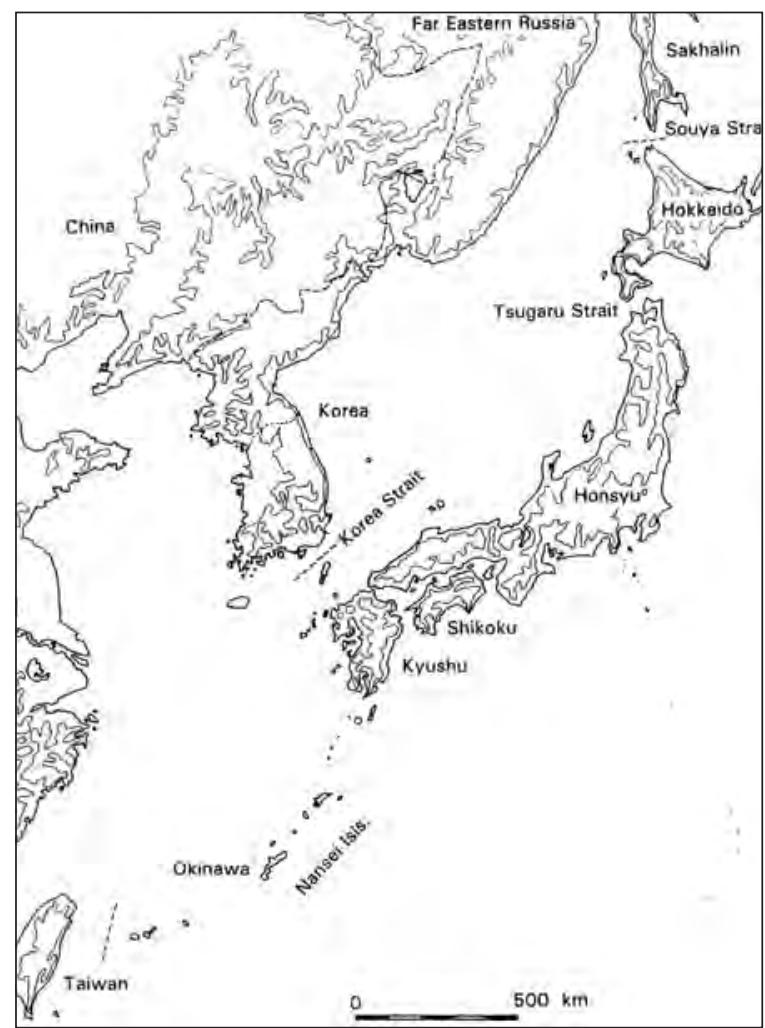

Fig. 1. Location of Japan (after Imamura 1996.Fig 1.1).

ted that ornaments on figurines were so unrecognizable that it was uncertain if the ornaments were realistic or not, and suggested a classification of figurines into 5 groups, with distributional maps (Kono 1928). However, taking only figurines into account, it was difficult to determine their chronology. Analysis of not only chronological change in figurines, but also regional differences was needed to understand the chronology. In the 1930s, archaeologists came to realize that simple anthropological comparison was not effective to reconstruct the function of figurines in prehistoric society, and that a chronological and regional organisation of all types of figurines was necessary (Yawata 1939.9).

It was Esaka who ordered the different types of figurines according to a chronological and regional arrangement (Esaka 1960). He clarified the chronological relationship between pottery types and figurine types, and revealed that every figurine type belonged to a specific span of pottery type. After his work, it was recognized that each type of figurine clearly indicated the time and the area to which it belonged.
Tab. 1. Radiocarbon dates of the Jomon period (after Taniguchi 2001. Tab. 1). 


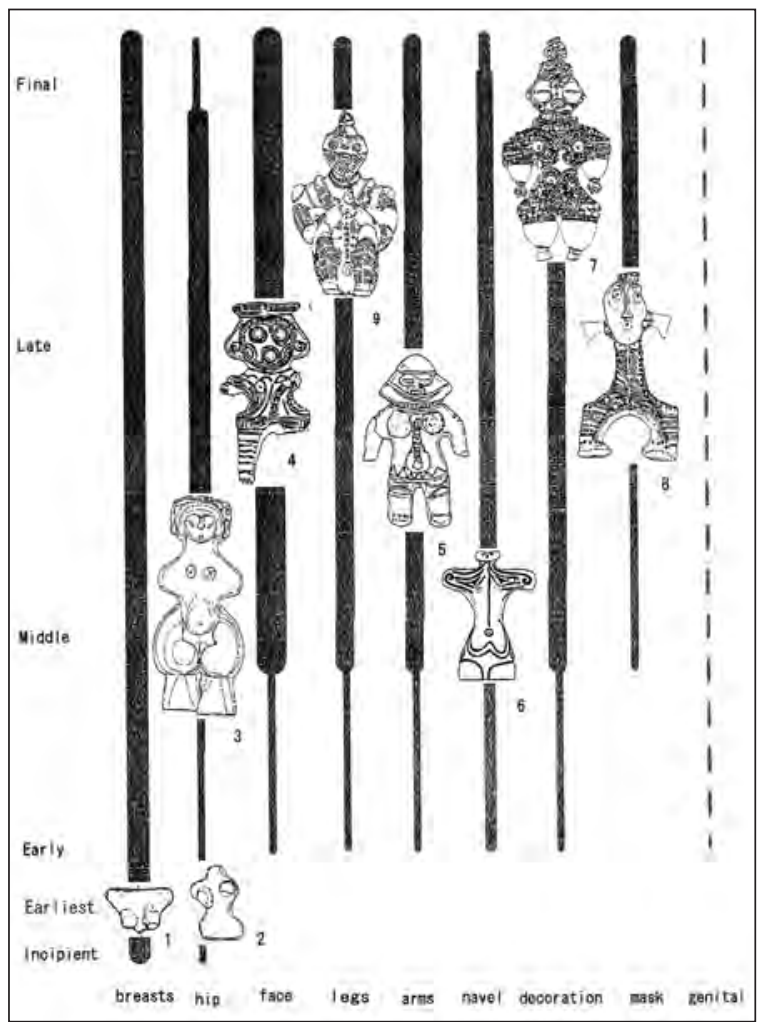

Fig. 2. Jomon figurine diversity (after Matsumoto 2004.Fig. 1).

If the decoration on figurines and pottery is the same, it is possible to determine their dates. In fact, it is not so simple. Nagamine (1977.158-159) asserted that in the case of dating figurines, there is no other way except analysis of the strata in which the figurines and pottery are contained. Theoretically, his assertion is correct, but theory and practice do not necessarily coincide. The subdivision of strata is not clear enough to enable the precise dating of figurines. This fact is promoted by the typological approach to the chronology of figurines. Archaeologists started to typologically subdivide the types of figurines (Suzuki 1981; Takano 1983). For example, decorations on some types of figurines were rich enough to be subdivided.

Accumulation of uncovered figurines after the 1970s enabled archaeologists to analyze figurines typologically. According to the increase of the excavations in different regions, information about the figurines was not transparent among all regions. The national museum encouraged all Japanese regions to facilitate the counting of figurines (Yaegashi 1992). Later, symposiums were held to share the collected information (The society of Saitama archaeology and The society of information about figurines 1992).

\section{THE CHRONOLOGICAL CHANGE IN FIGURINES}

Japanese figurines were already introduced in the English literature, but introduced figurines contained only elaborate examples from various periods (Imamura 1996.95-99, Figs 8.7-8). There is chronological and regional diversity of anthropomorphic clay figurines in the Jomon period (Fig. 2). This diversity should be clarified first.

Generally, the shape and design of figurines in Japan became gradually more complicated. The first figurines were made in the Incipient Jomon, dated to $10000-9000 \mathrm{BC}$. They had a schematic shape, which is a combination of triangular pads. Despite the fact that they were the oldest figurines, they already had representation of breasts.

Figurines from the Earliest Jomon were similar to those from the Incipient Jomon. Breasts were not necessarily represented. Triangular shapes still exited without representations of a head, arms or legs. In the Early Jomon period, the head of figurines were accentuated while arms and legs were schematized. The shape of figurines became naturalized. In the Middle Jomon period, the number of figurines drastically increased and some of the figurines were larger than before. They were of three-dimensional

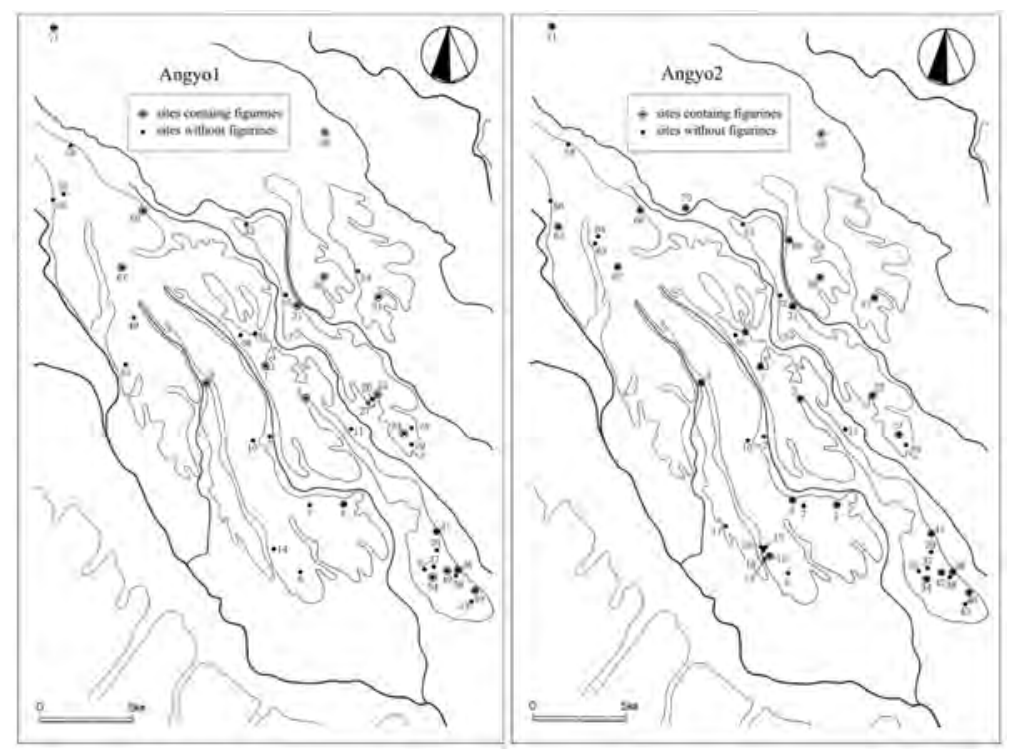

Fig. 3. Distribution of sites Angyo 1-2. 

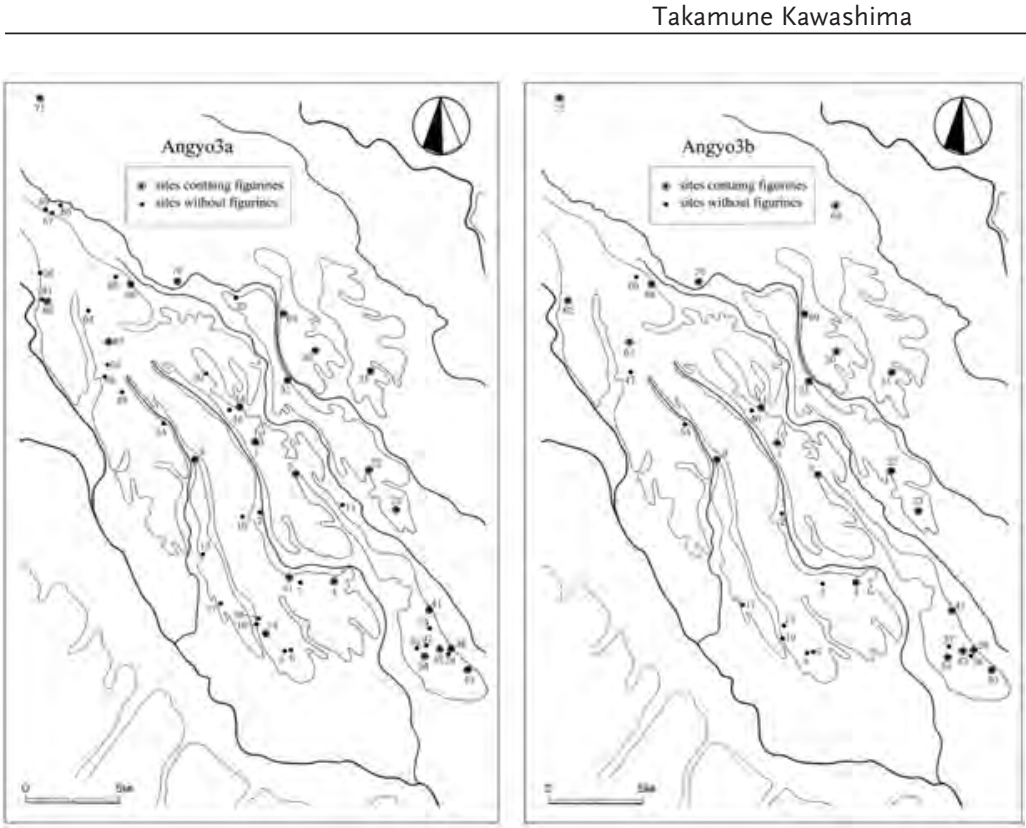

Omiya tableland where many excavations were carried out. The Omiya tableland is surrounded by two rivers, and its shape is long and narrow in north east-southwest axis, which is $35 \mathrm{~km}$ long and $20 \mathrm{~km}$ wide. Small rivers divide the Omiya tableland into several parts, forming a shape similar to the branches of a tree. The altitude of this tableland is 15 to $30 \mathrm{~m}$.

In the Omiya tableland, approximately 280 figurines from the Angyo period were uncovered from 25 out of 76 sites (Figs. 3-
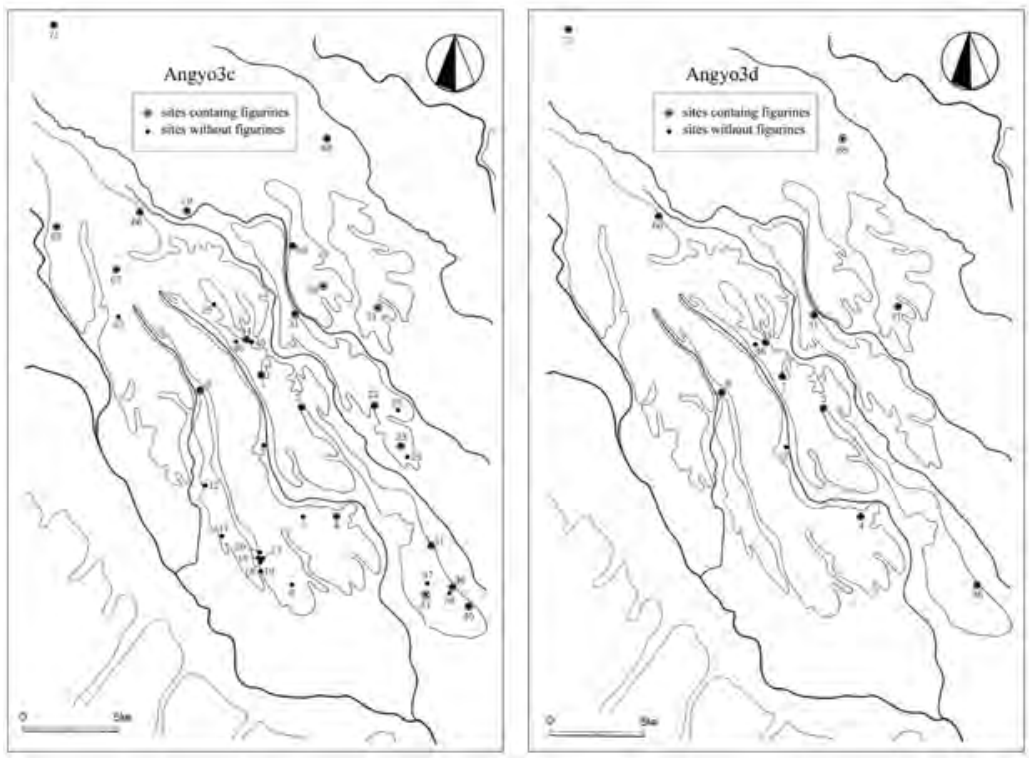

Fig. 4. Distribution of sites Angyo 3a-3d. 4, Tab. 2). It is noteworthy that the figurines were not discovered in every site, and that distribution is not even among the sites which contained figurines. Figurines in the Angyo period are classified into Owl-faced figurines, Snow- glassed figurines and I-marked figurines. In addition to these three figurine types, there were figurines which could not be classified because they lacked decorations and were found in small pieces. However, these figurines have not been analyzed in the same chronological context. In order to understand their chronological distribution, I arranged these figurines according to current studies.

shape and hollow structure. Human faces were clearly represented on figurines. In the Late Jomon, the distribution of figurines spread to the western and southern parts of Japan. Some figurines in the Latest Jomon were regarded as the masterpieces of Jomon Period, because of their elaborate design. In the latter part of the Latest Jomon figurines decreased and were rarely produced.

\section{A CASE FROM THE OMIYA TABLELAND}

As mentioned above, there were many regional and chronological differences in figurines during the Jomon period. I studied the figurines produced during the Angyo period, dated approximately from 1200 $\mathrm{BC}$ to $800 \mathrm{BC}$. The figurines were discovered in the

\section{Chronological position}

The chronological approach is popular among Japanese archaeologists. Owl-faced figurines have various decorations. Kawarabuki analyzed Owl-faced figurine form and proposed a chronological order for these figurines (Kawarabuki 1992.180). However, the problem is, that form sometimes shows the differences in regions, and that the change of form can be so slow that it is not visible. In order to compare the figurines with pottery, Suzuki analyzed decorative detail on Owl-faced figurines (Suzuki 1989.5162). Decorations on Owl-faced figurines, Snow-glassed figurines and I-marked figurines showed their chronological position (Hamano 1993.86-96; $\mathrm{Ka}$ neko 1993.145-149; Horikoshi 1993.114-118). However there are figurines from the Omiya table- 


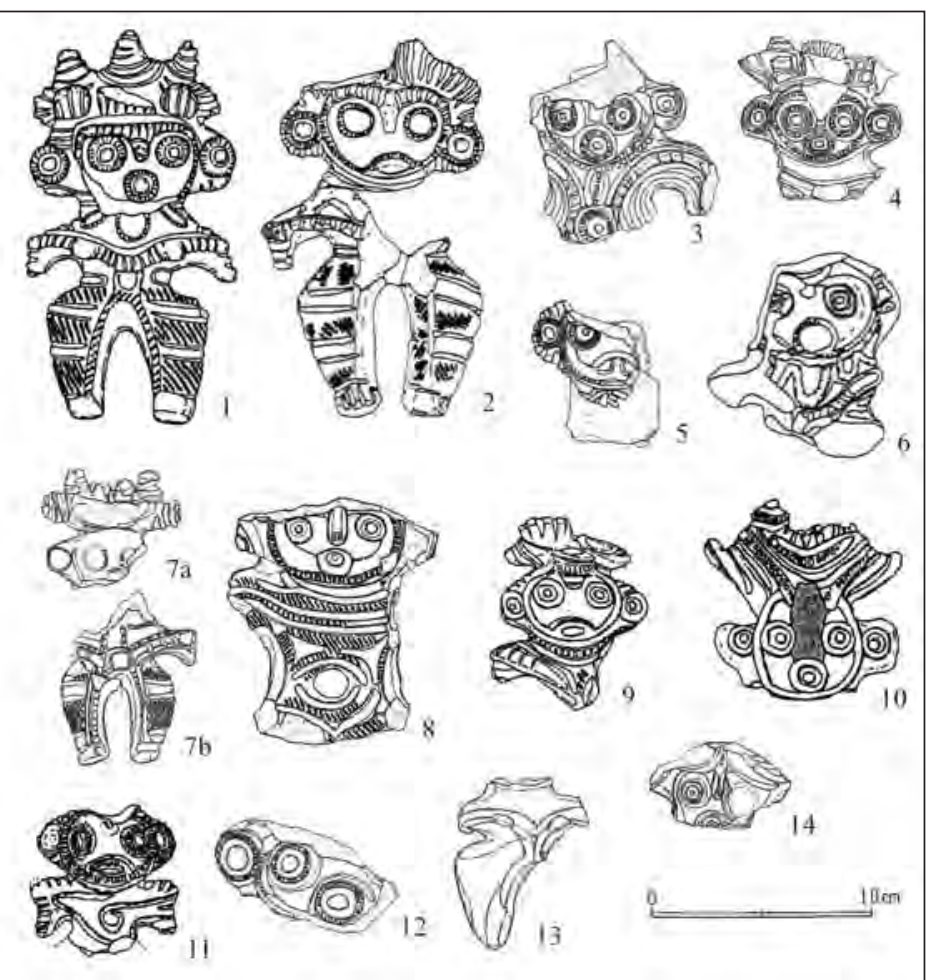

Fig. 5. Owl-faced figurines. 1 Takimamuro, 2, 9 Kohukasaku, 3, 7a-7b, 12-14 Sasara, 4-5 Utaya, 6 Gojin'yama, 8 Akagi, 10 Takaihigashi, 11 Kuroyatabatamae. 3c. Before the spread of Snow-glassed figurines, a new exotic type of decoration, which was used on pottery in the northern part of Japan, diffused to other areas, not only on pottery but also on other materials like figurines.

After the introduction of the new design, another type of figurine was made in the Omiya tableland, called Snowglassed figurine (Fig. 6). According to its comparison with the northern Snowglassed figurine type, Snow-glassed figurines from the Omiya tableland were not imported (Kaneko 1993.149). Snowglassed figurines were categorized into two groups. The first group was hollow with elaborate decorations, and the size was generally large, for example $30 \mathrm{~cm}$ tall. The second group was small and solid. In the central part of Japan (including the Omiya tableland) the latter group was rarely copied.

Snow-glassed figurines were introduced to and produced in the Omiya tableland. land which are not yet classified. Such unknown figurines are not the subject of this paper.

The Angyo period was subdivided into 6 periods, from Angyo1 to Angyo3d. In the Omiya tableland, the oldest Owl-faced figurines belonged to the Angyo 2 period. It is asserted that Owl-faced figurines were produced in the region where Angyo pottery originated (Fig. 5). However, from the Angyo3a period, Owl-faced figurines were influenced by northern culture, which produced Snow-glassed figurines. The influence was mainly observed in decoration on Owl-faced figurines, not in the shape, which in fact little changed until Owl-faced figurines disappeared in Angyo

\begin{tabular}{|c|c|c|c|c|c|c|}
\hline No. Sites & Total & $\begin{array}{c}\text { Owl- } \\
\text { faced }\end{array}$ & $\begin{array}{l}\text { Hollow } \\
\text { Owl-faced }\end{array}$ & $\begin{array}{c}\text { Snow- } \\
\text { glassed }\end{array}$ & I-marked & unknown \\
\hline 1 Higashikitahara & 5 & 4 & & & & 1 \\
\hline 3 Kohukasaku & 15 & 7 & 1 & & 1 & 6 \\
\hline 4 Banbaomuroyama & 3 & & & 1 & & 2 \\
\hline 8 Maekubonishi & 1 & 1 & & & & \\
\hline 9 Narasedo & 7 & 4 & & 1 & & 2 \\
\hline 15 Otohonmura No.5 & 1 & & & & & 1 \\
\hline 21 Urajionji & 2 & 2 & & & & \\
\hline 22 Shinpukuji & 6 & 1 & & 3 & & 2 \\
\hline 23 Kuroyatabatamae & 12 & 4 & & 7 & & 1 \\
\hline 30 Utaya & 42 & 23 & & 1 & & 18 \\
\hline 31 Sasara & 43 & 21 & & 2 & 3 & 17 \\
\hline 34 Ishigami & 7 & 5 & & 1 & & 1 \\
\hline 36 Sarugaikita & 1 & & & 1 & & \\
\hline 40 Shingou & 2 & & & & & 2 \\
\hline 41 Shojinba & 1 & & 1 & & & \\
\hline 42 Akayama & 2 & & & & & 2 \\
\hline 44 Juyonbankochi & 1 & & & & & 1 \\
\hline 62 Tomiokahikawajinjamae & 2 & & & 2 & & \\
\hline 66 Ushiroya & 13 & 4 & & 4 & 2 & 3 \\
\hline 67 Takaihigashi & 23 & 5 & 1 & & & 17 \\
\hline 68 Gojin'yama & 3 & 1 & & & & 2 \\
\hline 69 Irigochi & & & & & & \\
\hline 70 Kotsuka & 1 & 1 & & & & \\
\hline $71 \quad$ Akagi & 84 & 15 & 4 & 19 & & 46 \\
\hline \multirow[t]{2}{*}{77 Takimamuro } & 1 & 1 & & & & \\
\hline & 278 & 99 & 7 & 42 & 6 & 124 \\
\hline
\end{tabular}

Tab. 2. Angyo sites in the Omiya tableland 
Moreover, influence from northern Japan was observed in Owl-faced figurines. Some exceptional large size hollow Owl-faced figurines appeared (Fig. 7). Such Owl-faced figurines had a different body shape, but the same face representation as solid Owl-faced figurines. The following are some interpretations about their appearance. I suggest that the large and hollow Owl-faced figurines were influenced by Snowglassed figurines, because of following reasons: (1) the lack of hollow figurines in central Japan around the Omiya tableland, (2) the appearance of large and hollow Owl-faced figurines at the stage of introduction of Snow-glassed figurines into the Omiya tableland and (3) a larger size in comparison to solid Owlfaced figurine.

Although influenced by northern cultures, not only Snow-glassed figurines but also Owl-faced figurines were still produced. At the end of the Angyo period, figurines drastically decreased and I-marked figurines were rarely produced (Fig. 8). Originally, the Imark design was not used on figurines, but on clay tablets, stone sticks and so on (Takano 1983.69). In Angyo3d, the I-mark was used for figurines.

In the Angyo period, which defined the Angyo pottery type, not only pottery but also figurines changed from Owl-faced to I-marked figurines. During the Angyo period, three types of figurines appeared. Owl-faced figurine originated in this region and was constantly produced. Hollow Owl-faced figurine appeared under the influence from northern culture. Snow-glassed figurine was copied and coexisted with Owl-faced figurine. After the production of Snowglassed figurine, few I-marked figurines were produced.

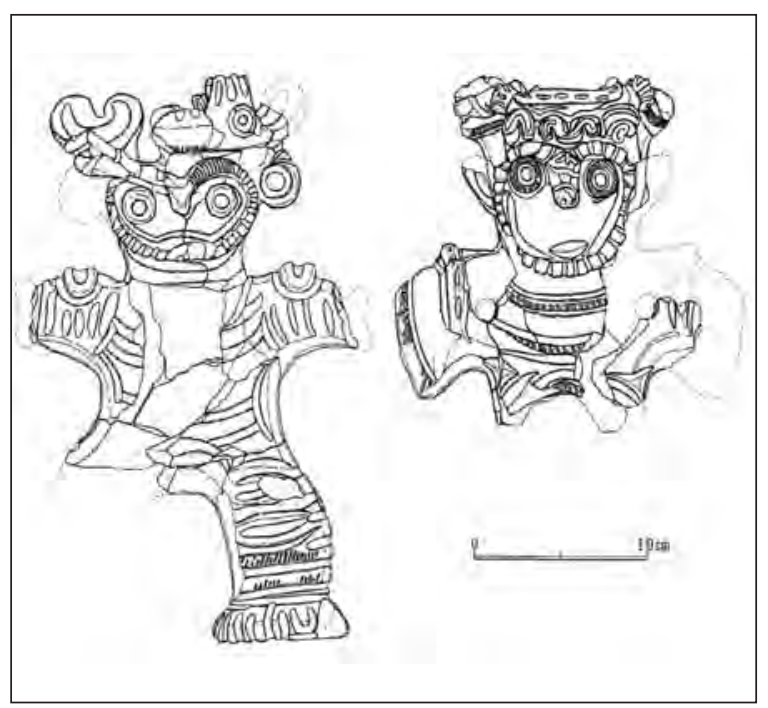

Fig. 7. Hollow Owl-faced figurines from Akagi.

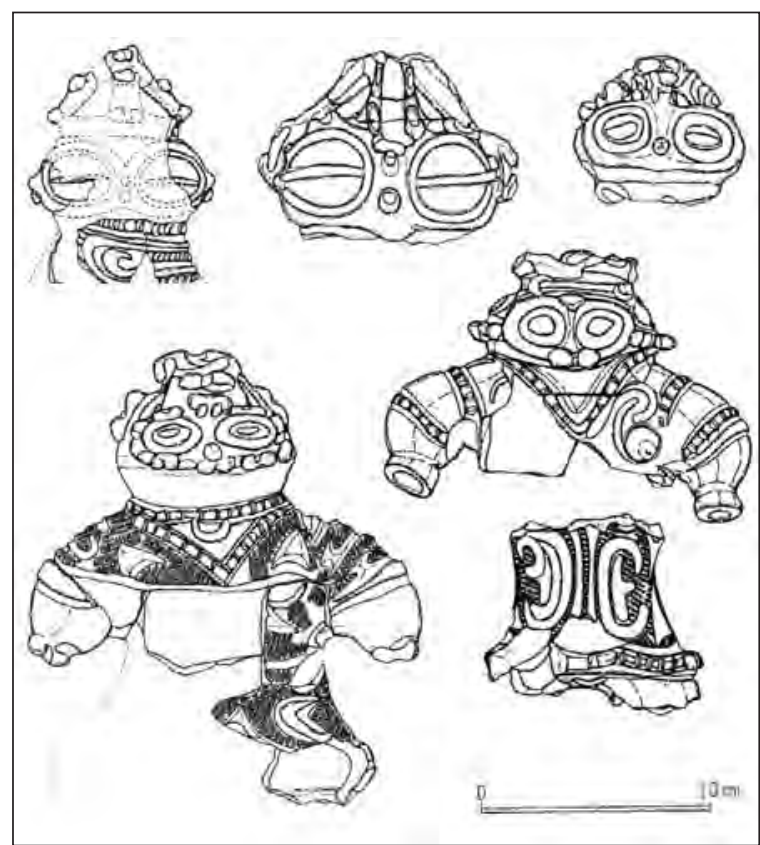

Fig. 6. Snow-glassed figurines from Akagi.

\section{CHARACTER OF SITES AND DISTRIBUTION OF FIGURINES}

There are some differences between the sites containing figurines and those without them. Large amounts of different kinds of remains were excavated from the sites in which figurines were discovered. Various kinds of artefacts which were used for hunting and settlements use were discovered in sites containing figurines, for example arrow heads, stone axes, grind stones and so on. In the Angyo period, with the exception of the sites containing figurines, houses have rarely been discovered. It could be claimed that many more artefacts were discovered from sites containing figurines than from sites without them.

It is noteworthy that sites containing figurines were occupied for a longer time than other sites. It is not necessary that figurines were discovered from every stage in the sites. Nonetheless, there is a tendency that the sites with figurines continued to be occupied longer. Figure 9 shows that after Angyo 3b, in spite of a decrease in sites, most sites with figurines still existed. This indicates that figurines were kept in the settlements which left various kinds of remains, and moreover, that the act of keeping figurines could have been related to the long term occupation of settlements.

Out of 25 sites from which figurines were discovered, Akagi site, Utaya site and Sasara site need spe- 
cial attention. Table 2 shows the number of figurines which were uncovered from these sites. From Utaya and Sasara over 20 0wl-faced figurines were discovered, however there were only one or two Snow-glassed figurines. On the other hand, many Snow-glassed figurines were discovered at Akagi site, which also contained 15 0wl-faced figurines. Sasara and Utaya sites were located nearby. Akagi site was not located far from the Sasara and Utaya sites, but there was a great difference between Akagi and the other two sites.

Snow-glassed figurines were made during Angyo $3 \mathrm{~b}$ and Angyo 3c. At the Akagi site, there were no Angyo 3c Owl-faced figurines, but Angyo 3b Owl-faced figurines. Therefore, I expect that at the Akagi site the main figurine type changed from Angyo $3 \mathrm{~b}$ to Angyo 3c. Moreover, there were 19 Snow-glassed figurines in Akagi site, which comprises $45 \%$ of the Snow-glassed figurines from the Omiya tablelands. Since the Snow-glassed figurines were only copied and not originally made in the Omiya tablelands, it seems that the information about these exotic figurines was brought to the Akagi site from the northern areas. In Akagi site, the presence of hollow Owlfaced figurines, which were influenced by Snow-glassed figurines, could support a hypothesis for the uneven distribution of information.

\section{FUNCTION OF FIGURINES}

Even in the Omiya tableland, where excavations were frequently carried out, figurines from the Angyo period were not numerous and were not uncovered from every Angyo site. The sites which contained these figurines are not even included in the amount and content of figurines. Moreover, the quan-

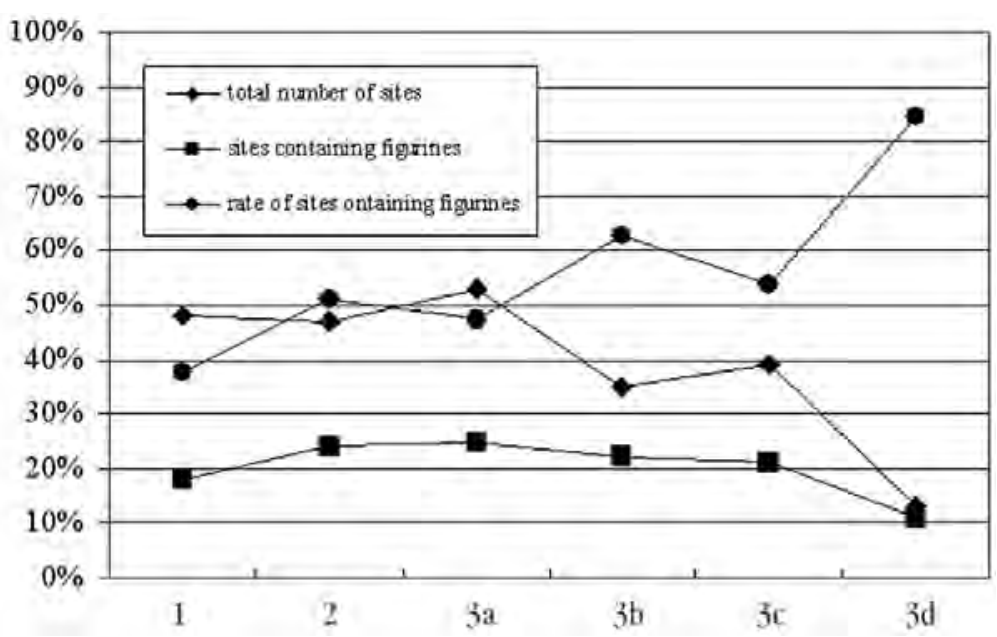

Fig. 9. Transition in site numbers.

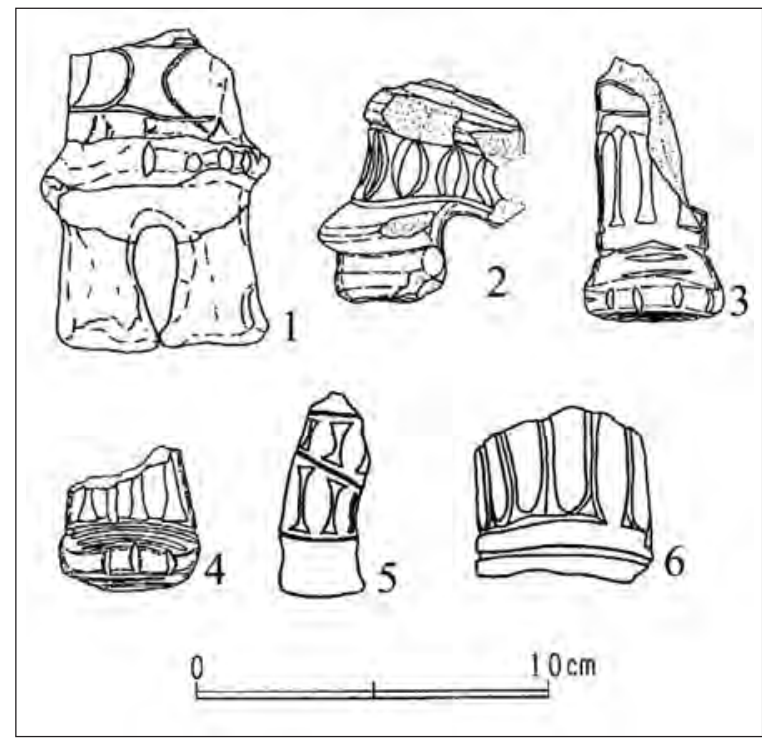

Fig. 8. I-marked figurines. 1 Kohukasaku, 2-4 Sasara, 5-6 Ushiroya.

tity and quality of figurines differs among the sites. According to these facts, the function of figurines should be reconsidered.

During the Angyo period, both Owl-faced and Snowglassed figurines were mainly produced in Angyo 2$3 \mathrm{c}$. The total number of both types of figurines was 141. As the Angyo period is thought to have lasted for at least 400 years, there were not enough figurines to be utilized every year at every site. This would bring us to an assumption that figurines were connected to specific settlements and not consumed every year.

In the previous section on the history of figurine studies, I mentioned assumptions that the figurines may have been used as toys for children, amulets for an easy birth and so on. But if personal use was their principle function within Jomon society, numerous figurines would have been produced, or they would have been evenly distributed.

If the function of figurines was only fragmentation, the total number of uncovered figurines would be larger. The function of figurines must have been related to some long-term customs, which were held within specific settlements. Archaeologists, when they found figurines, saw only their final position and final location in an archaeological site. But, if we consider how figurines were used in 
prehistoric society, not only deliberate fragmentation, but also the presence of figurines in settlements should be considered. There is a possibility that figurines were used or kept in settlements much longer than most archaeologists suspected.

Finally, it can be asserted that the

\begin{tabular}{|l|c|c|c|}
\hline & $\begin{array}{c}\text { total number } \\
\text { of sites }\end{array}$ & $\begin{array}{c}\text { sites containing } \\
\text { figurines }\end{array}$ & $\begin{array}{c}\text { rate of sites } \\
\text { containing figurines (\%) }\end{array}$ \\
\hline Angyo 1 & 48 & 18 & 37.5 \\
\hline Angyo 2 & 47 & 24 & 51.1 \\
\hline Angyo 3a & 53 & 25 & 47.2 \\
\hline Angyo 3b & 35 & 22 & 62.9 \\
\hline Angyo 3c & 39 & 21 & 53.8 \\
\hline Angyo 3d & 13 & 11 & 84.6 \\
\hline
\end{tabular}

Tab. 3. Transition in site numbers.

presence of figurines influenced not only a settlement but also neighbouring sites. I propose that figurines were treated as monuments to deities and used for the formation of identity in settlements.

\section{CONCLUSION}

In this article, I analyzed almost all the Angyo figurines from sites distributed in the Omiya tableland. As I focused on every site, including the sites where figurines were not discovered, the precise distribution of figurines became evident. First, according to detailed chronological analysis of figurines, I clarified that figurines were not produced throughout the Angyo period. Second, distribution of sites revealed that figurines were unevenly distributed in the Omiya tableland. There were differences between the sites containing figurines and the sites without them. Although the decrease in figurines was somehow connected with the decrease in sites, the sites containing figurines were occupied longer.

In addition, the figurines were made carefully. Clay for figurines was selected with the same attention as clay for pottery, and decorations were carefully attached to figurines. Elaborate figurines painted red must have been treated carefully and respectfully, because the red colour was thought to be sacred.

Former studies asserted that deliberate fragmentation existed as a ritual act, and could be the reason for the broken figurines. However, I concluded that the function was not limited to fragmentation, and that one of the functions was their presence in settlements. I also suggest that there is little possibility that figurines belonged to ordinary people. This does not completely exclude deliberate fragmentation, but in the case of figurine studies, emphasis should not be placed only on deliberate fragmentation.

\section{REFERENCES}

CHAPMAN J. 2000. Fragmentation in archaeology. People, places, and broken objects in the prehistory of south-eastern Europe. Routledge. London.

ESAKA T. 1960. Figurines. Azekurashobo. Tokyo. (in Japanese).

FUJINUMA K. 1997. Jomon figurines. Kodansha. Tokyo. (in Japanese).

HAMANO M. 1993. A study of Snow-glassed figurines. Bulletin of Saitama archaeological agency 10: 83114 (in Japanese).

HORIKOSHI M. 1993. I-marked figurines. Saitama archaeology 30. The society of Saitama archaeology. 109-119 (in Japanese).
IMAMURA K. 1996. Prehistoric Japan: new perspectives on insular East Asia. UCL press. London.

JENSEN A. E. 1977. (Translated by T. Obayashi, I. Ushijima, and D. Higuchi). Die getötete Gottheit. Kobundo. Tokyo. (in Japanese).

KANEKO A. 1993. Snow-glassed figurines in Kanto district: comparison with original Snow-glassed figurines. Saitama archaeology 30: 139-171 (in Japanese).

KAWARABUKI T. 1992. Figurines in Ibaraki prefecture. In S. Yaegashi (ed.), The information about figurines. Bulletin of the national museum of Japanese history 37: 175-184 (in Japanese). 
KONO I. 1928. Outline of prehistoric figurines in Japan. In S. Sugiyama (ed.), Prehistoric art in Japan (in Japanese).

MATSUMOTO N. 2004. Universality and singularlity in Jomon ideology:the case of clay figurines. In The society of Archaeoloical studies (ed.), Cultural diversity and the archaeology of the 21st century: 150165 (in Japanese and English).

MIZUNO M. 1974. Reconstruction of figurine rituals. Shinano 26-4: 12-26.

NAGAMINE K. 1977. Figurines as magical objects. In K. Nagamine and M. Mizuno (eds.), A compendium of prehistoric art in Japan 3: 155-171 (in Japanese).

ONO U. 1910. Chronological study of figurines. Journal of anthropology of Tokyo 296: 54-60 (in Japanese).

ONO M. 1984. Technique of making figurine. Kaiji 50: 19-22 (in Japanese).

The society of Saitama archaeology and The society of information about figurines (eds.) 1992. Angyo culture: meeting point for pottery type and figurine type. Saitama archaeology. extra issue 4. Saitama. (in Japanese).

SUZUKI K. 1981. Introduction of figurine studies. Annual report of Aomori local museum 6: 65-108 (in Japanese).

SUZUKI M. 1989. Fundamental study of Angyo figurines. Antiquity 87: 49-95 (in Japanese).

TAKANO M. 1983. Memo for figurines from Angyo period. Public opinion of history 9-9: 65-70 (in Japanese).

YAWATA I. 1939. A question of cult in prehistoric Japan. In K. Nagasaka (ed.), Anthropology and prehistory 13: 1-18 (in Japanese).

YAEGASHI S. (ed.). 1992. The information about figurines. Bulletin of the national museum of Japanese history 37. Sakura. (in Japanese).

YOSHIDA A. 1986. Mythology of Jomon figurines. Meichokankokai. Tokyo. (in Japanese). 